\title{
A perversão como estética política para a sexualidade: notas sobre a revista Nin
}

Muriel Emídio Pessoa do Amaral

Claudio Bertolli Filho

Maria Manuel Rocha Teixeira Baptista

A proposta desse texto é de aprofundar como os conceitos de perversão e política podem ser aplicados no reconhecimento e visibilidade da diversidade de práticas e orientações sexuais. Neste momento, a perversão não será compreendida como algo nocivo ou repugnante, mas como manifestação que propõe o desafio às estruturas de poder e que pode tornar-se ação política como manifestação pública de visibilidade. Para esse efeito, foi escolhido como objeto de estudo a revista brasileira Nin para ser analisada e perceber como os discursos e representações de corpos e de sexualidades podem ser desafiadoras de discursos de poder, além de oferecer outras interfaces de reconhecimento de sujeitos e sexualidades.

A perversão pode ser compreendida sob vários aspectos, inclusive a partir de pontos de vista que podem dialogar com aberrações sexuais (práticas reprováveis que são reconhecidas de acordo com o valor histórico) ou comportamentos adversos à sociedade (humilhações, assassinatos, flagelação do outro, etc...), da mesma forma que perversa pode ser também o comportamento que, de alguma forma, realiza alguma atividade ou ação de enfrentamento. Por outro lado, o desafio às estruturas de poder advém da própria condição da perversão enquanto condição estruturante do psiquismo para a obtenção do gozo, sobre essa condição, a moral perversa reinventa a condição social pela oferta de visibilidade a representações e signos que são abafados e reprimidos por uma questão de discursiva do poder. Nesse caso, o enfrentamento proposto é para alargar a representatividade do corpo em representações midiáticas para além das representações ausentes de mácula, além do desafio de conjugar na mesma proposta editorial homens, mulheres, travestis e transexuais, uma espécie de afrontamento à heteronormatividade compulsória e à estigmatização da diversidade sexual.

A partir do conceito de perversão que pode ser compreendido como resistência para reconhecimento das sexualidades e desejos no cenário político, enquanto afronta às estruturas de poder, esse artigo pretende reconhecer como essa ideia pode ser empreendida como força para ressignificação e simbolização para enfrentamentos sobre as condições cristalizadas em discursos midiáticos sobre corpos, identidades e sexualidades. O objeto 
empírico escolhido para este estudo é a revista erótica Nin. A publicação propõe enfraquecer as demarcações das sexualidades e identidades, expandindo novos horizontes acerca do desejo e representações do corpo. O título da revista é uma alusão ao nome de Anaïs Nin, escritora francesa reconhecida internacionalmente pela literatura erótica que produziu a partir dos anos de 1930. Nin é brasileira, produzida na cidade do Rio de Janeiro, sob o selo da editora Guarda-chuva, coordenada por Alice Galeffi e Letícia Gicovate e até agora apresenta duas edições: a de 2015 e a de 2016.

A linha editorial de Nin não traz apenas ensaios fotográficos e desenhos eróticos, mas também apresenta entrevistas com personalidades que, de alguma forma, estão envolvidas na temática da sexualidade, como é o caso da primeira edição que trouxe a entrevista com a ex-atriz pornô Cicciolina. Para além disso, a revista também apresenta textos que se aproximam da produção científica com reflexões acadêmicas e posicionamentos sobre teorias acerca de temas referentes à sexualidade, arte e sociabilidades, bem como uma série de desenhos, ilustrações e imagens também permeando a temática da sexualidade. A proposta da revista é algo que inovador dentro do ramo das publicações eróticas; refletir a sexualidade para em entrosamento com textos de abordagem acadêmica é desmistificar o desejo para a vida comum de modo simples. Assim, os textos, ilustrações e fotografias apresentam de modo simples aquilo que insiste em permanecer no limbo das representações do sexo por uma questão discursiva de poder. Como exemplo, o avanço de discursos conservadores até mesmo na política representativa do Congresso brasileiro que impossibilita avanço de discussões sobre a legalização do aborto, a penalização por crimes de feminicídio, até mesmo a atuação de instituições religiosas que se tornam gargalos para a discussões sobre gênero e sexualidade que persistem na permanência de estruturas patriarcais e misóginas.

Ultrapassando as linhas editorias convencionais de publicações eróticas, Nin pode ser considerada como sendo de discurso perverso à medida que enfrenta paradigmas e estereótipos do desejo, das sexualidades e das identidades que dialogam com as estruturas heteronormativas, trazendo, deste modo, para visibilidade política as sexualidades dissidentes e novas representações de desejo. Neste contexto, essa pesquisa se apoia na concepção de Hannah Arendt (1992) sobre política ao reconhecer corolário entre política e visibilidade e também a aplicação da estética como um modo de partilha social e cultural enquanto manifestação política, como identificou Jacques Rancière (2005) sobre o tema. Amaral e Arias Neto (2018) consideraram a revista como sendo perversa e positiva justamente pelo desafio às formas de poder que possam trazer aspectos positivos à 
sociedade, entretanto, para além dessa condição, a perversão empreendida pela revista oferece signos políticos de visibilidade e representação para corpos e subjetividades, principalmente de sujeitos marginalizados pela sexualidade ou pobreza.

Para isso, neste texto, o conceito de perversão vai para além do lugar comum de ser considerada manifestação danosa à sociedade ou ao indivíduo, mas como sendo uma potência de criatividade, grandeza e desafio (Roudinesco 2008) por não se sujeitar a ditames fechados de atuação, como será abordado no decorrer desse texto. Paralelamente a esse conceito, esse ensaio apoia-se em Foucault ao abordar as concepções de poder na sociedade que estão presentes nas práticas cotidianas e, algumas vezes, sutis, práticas e discursos de sujeitos, grupos ou instituições. De acordo com o autor, o discurso é uma tecnologia de poder que tem como um dos fundamentos a ação. Assim, a insubmissão aos discursos naturalizados torna-se uma estratégia de perversão ao promover desafios e enfrentamentos para o exercício da política e também da cidadania.

\section{Procedimentos teóricos e metodológicos}

Nos discursos comuns e estereotipados, as perversões são traçadas em referências associadas a ações, discursos e práticas agressivos e repugnantes como o usufruto da condição do outro para o gozo ou aquelas consideradas de cunho sexual como a zoofilia, pedofilia e incesto. Entretanto, para além dessas concepções, que também são legítimas segundo recortes históricos e culturais, há outras formas de representação das perversões que podem ser compreendidas como importantes e necessárias para o cenário político enquanto estratégias de visibilidade para indivíduos marginalizados por uma questão de poder, um desafio às estruturas sufocantes do sistema que persiste na domesticação de corpos e subjetividades.

Para reconhecer os movimentos efetuados pelas práticas perversas a que nos referimos é importante o reconhecimento do quadro histórico destas representações. As perversões foram consideradas repugnantes pelo viés moral, quando associadas a comportamentos aberrantes sexuais que não se enquadrariam em valores socialmente partilhados. De acordo com Foucault (2012: 44), foi a partir do começo do século XIX com o desenvolvimento do pensamento científico e a reprodução dos valores dos discursos médicos e da saúde, e também jurídicos, que foram estabelecidos referenciais culturais sobre 
aquilo que poderia ser normal ou anormal, aquilo que deveria ser acompanhado, controlado, disciplinado, verificado e analisado segundo a perspectiva da ciência para categorização sobre o que é normal ou patológico. A normalidade seria uma questão atravessada pelos códigos morais e de poder, refratando subjetividades e domesticando corpos. Assim, aquilo que ultrapassasse a curvatura da normalidade poderia ser considerado como uma ofensa social, uma condição perversa da condição humana.

Por esse ponto de vista, as homossexualidades, zoofilia, necrofilia, masturbação e comportamentos que operassem fora do esquadro da dita normalidade eram enquadrados como equivalentes a comportamentos desviantes e, consequentemente, da moral. Por esse modo, seriam comportamentos passíveis de tratamentos que visassem correções pela ordem social e econômica burguesa, o que poderia incluir também intervenção medicamentosa em caso de questões clínicas. Os discursos médicos e de saúde forjavam a condição do sujeito a par das práticas que seriam consideradas normais e economicamente produtivas. Além disso, pela visão de Foucault (2012: 45), esse modo de olhar a presença desses discursos na sociedade, na verdade, estabelece referências cristalizadas sobre poder e verdade. Como são discursos produzidos por sujeitos dotados do conhecimento científico, ou seja, signo de poder, esses enunciados tornam-se dispositivos de verdade à medida que passam a ser reverberados no meio social como uma condição de poder, além abordar também a questão do prazer:

O prazer se difunde através do poder cerceador e este fixa o prazer que acaba de desvendar. $\mathrm{O}$ exame médico, a investigação psiquiátrica, o relatório pedagógico e os controles familiares podem, muito bem, ter como objetivo global e aparente dizer não a todas as sexualidades errantes ou improdutivas, mas, na realidade, funcionam como mecanismos de dupla incitação: prazer e poder. Prazer em exercer um poder que questiona, fiscaliza, espreita, espia, investiga, apalpa, revela; e, por outro lado, prazer que se abrasa por ter que escapar a esse poder, fugir-lhe, enganá-lo ou travesti-lo. Poder que se deixa invadir pelo prazer que persegue e, diante dele, poder que se afirma no prazer de mostrar-se, de escandalizar ou de resistir. Captação e sedução; confronto e reforço recíprocos: pais e filhos, adulto e adolescente, educador e alunos, médico e doente, e o psiquiatra com sua histérica e seus perversos, não cessaram de desempenhar esse papel desde o século XIX. (Foucault 1993: 45) 
Desse modo, ainda na esteira do pensamento foucaultiano, a sexualidade tornou-se, à altura, um dispositivo de poder para legislar sobre questões de ordem social e cultural, não enquanto uma constituição tácita, mas presente, mesmo que de forma sutil, nas relações humanas, nos modos de sociabilidade e convivências. Como o próprio Foucault aponta ao dizer-se o sexo da criança quando nasce, tal ato revela por si só a construção social simbólica acerca da sexualidade e do gênero, além da formação identitária esperada socialmente sobre esse indivíduo. Na mesma medida em que há a necessidade de uniformização e padronização de corpos e subjetividades, o que não deixa de ser perverso por uma questão de viabilizar a subjetividade do indivíduo segundo condições heteronormativas, o próprio enfrentamento dos movimentos hegemônicos, enquanto força igualmente perversa, pode contribuir para a criação dos mecanismos de representação e visibilidade das diferentes sexualidades.

Vale lembrar também que a perversão foi considerada uma das condições estruturantes do psiquismo humano, segundo os estudos da Psicanálise desenvolvidos por Freud (1905/1996) e, posteriormente, por Jacques Lacan. De modo breve, a perversão para a Psicanálise passa a ser compreendida como o deslizamento sobre a castração simbólica de assujeição do indivíduo por uma relação de desejo e fantasia. Assim, na moral perversa, o sujeito busca a substituição do falo que fora castrado estabelecendo movimentos de fetichização e gozo pelas realidades montadas. Por isso, a perversão não seria apenas reconhecida como comportamentos, mas na relação de desejo, gozo e fantasia desenvolvida inconscientemente pelo sujeito.

Mesmo havendo a possibilidade de compreender a perversão como algo repugnante de aniquilamento, desumanização ou destruição do outro, há outras perspectivas que faz dela um sinal de sublimação adotado como referência para esse texto. Assim, perversão nesse recorte teórico-metodológico é compreendida como o enfretamento dos códigos que se encontram articulados a mecanismos de poder, sentidos que nem sempre se questionam, mas que, frequentemente, operam ou condicionam os modos de sociabilidade $\mathrm{e}$ representação. Como apresentado por Roudinesco:

(...) a perversão é também criatividade, superação de si, grandeza. (...) $\mathrm{O}$ fascínio exercido sobre nós pela perversão deve-se precisamente a que ela pode ser ora sublime, ora abjeta. Sublime, ao se manifestar nos rebeldes de 
caráter prometéico, que se negam a se submeter à lei dos homens, ao preço da sua própria exclusão; abjeta, ao se tornar, como no exercício das ditaduras mais ferozes, a expressão soberana de uma fria destruição de todo laço genealógico. (2008: 11)

Isto é, a perversão pode tornar-se um modo de simbolização de sentidos pela transgressão de valores. Por esses caminhos que os enfrentamentos podem constituir formas de resistências aos signos que foram erguidos sob a condição de poder, ainda mais aqueles feitos a par do deboche e da sátira, os quais podem ser considerados perversos à medida que desafiam os discursos que já se encontram marmorizados. Torna-se perverso a partir do momento que desafora a moral vigente na intenção de provocar a subversão da sexualidade como condição moralizante.

É no âmbito desse quadro teórico que esse texto pretende compreender como a revista Nin, publicação erótica brasileira, consegue estabelecer diálogos entre perversão, política e sexualidade ao expor de maneira clara uma gama muito diversa de representações sobre sexualidades e gêneros.

\section{A epistemologia queer como manifesto político e artístico}

A revista Nin passou a circular em 2015 sob o aspecto de ser uma revista erótica. Talvez, esta seja a única referência de algum traço de identidade atribuído à publicação, ao contrário da demais publicações voltadas a essa temática em que há a delimitação precisa e específica a que público se destina. A iniciativa de delimitação quanto ao público para a revista em questão pode ser uma tarefa insignificante e desprovida de sentido. Imagens de homens robustos ou magros, peludos ou lisos repartem as páginas com mulheres mais maduras, suburbanas, jovens e uma série de outras representações de gênero e sexualidade, o que incluem gays, travestis, lésbicas, mulheres negras e brancas.

Desse modo, verifica-se que a revista não se estabiliza em alicerces rigidamente impostos para as representações delimitadas das sexualidades; ao contrário, transita, movese, desloca-se e, inclusive, e porque não principalmente, incomoda as estruturas que parecem revelar-se mais estáveis. Por isso que Nin dialoga com as estéticas e epistemologias 
queer, a necessidade de despressurização de marcas de identidade. Nascido a partir dos Estudos Culturais e pelos movimentos feministas e pós-estruturalistas, o termo queer referese àquilo que é abjeto, estranho, esquisito, uma denominação que foi utilizada para compreender os sujeitos reconhecidos como sendo homossexuais, independentemente do sexo. Entretanto, a necessidade de contemplar a variedade de sexualidades, o sexo como uma desinência biológica tornou-se frágil para representar a uma gama tão extensa de subjetividades que não podem mais ser ignorada no meio político; surge nesse cenário o desenvolvimento da epistemologia queer. Por esse pensamento que Louro considera que "queer permite pensar a ambiguidade, a multiplicidade e a fluidez das identidades sexuais e de gênero, mas, além disso, também sugere novas formas de pensar a cultura, o conhecimento, o poder e a educação" (2001: 550).

No sentido semelhante que Butler (2003: 36) considerou que as instâncias biológicas não seriam suficientemente fortes para reconhecer as sexualidades e que as homossexualidades não seriam suficientemente adequadas e exclusivas para compreender as diversas manifestações subjetivas das sexualidades e dos gêneros. Desse modo, a autora acredita que as sexualidades sejam compreendidas como performatividade, isto é, amparada sob a concepção de Foucault de que o discurso é um dispositivo de poder, a sexualidade para Butler também segue os mesmos trilhos. Um exemplo é o reconhecimento do sexo de uma criança já traça as expectativas, comportamentos e atitudes esperadas desse sujeito, por isso a heterossexualidade compulsória constitui-se como um discurso de poder para a formação dos corpos e subjetividades. Há a necessidade de forjar uma certa estabilidade sobre o sexo enquanto um mecanismo de manutenção de poder. Doravante, a intenção de romper esse paradigma traz à tona posicionamentos subjetivos para o reconhecimento da sexualidade, do corpo e do desejo, fora do esquadro normativo dos posicionamentos binários ou das referências biológicas, valorizando agora manifestações mais libertárias das subjetividades e de visibilidades.

Desse modo, a autora considera que as produções das sexualidades não apresentam linhas claras do caminho que irão traçar e vertem-se das propostas originais enquanto discursos de poder e "mobilizam inadvertidamente possibilidades de 'sujeitos' que não apenas ultrapassam os limites da inteligibilidade cultural como efetivamente expandem as fronteiras do que é de fato culturalmente inteligível" (Butler 2003: 54). Por isso, no entendimento da autora, o sexo é uma construção calcada na materialidade dos corpos e em formas de subjetividade específica. Por essa ótica também Barker e Jane (2016: 369), amparados nas concepções de Butler, concebem o termo queer como sendo aplicável à 
política no reconhecimento diversidade e pluralidade de identidades para além do entendimento da unidade entre as sexualidades, além de ser também uma expressão de resistência. O desenvolvimento desta epistemologia da performatividade e as qualidades envolvidas no potencial do conceito queer podem ser libertadoras ou mesmo perversas quando levarmos em consideração o pensamento de Silva sobre esse campo. Para o autor, o queer também tem como proposta "questionar, problematizar, contestar todas as formas bem-comportadas de conhecimento e de identidade. (...) é, neste sentido, perversa, subversiva, irreverente, profana, desrespeitosa" (Silva 2000: 107). A partir dessas considerações, as representações queers podem ser compreendidas como manifestações políticas de visibilidade de/a sujeitos e subjetividades marginais e marcados por estereótipos por discursos de poder.

Por outro lado, a processo de ter visibilidade nos espaços públicos dialoga com a proposta de Hannah Arendt (1992) sobre política. A autora apresenta os valores da Grécia clássica ao considerar que o termo política se refere a experiências em comunidade praticadas por homens livres na polis grega'. Cabe ao sujeito livre a própria visibilidade para a ação enquanto movimentos feitos em concerto, em interação, sociabilidades e comunicação com os demais da polis. Em consequência, segundo o pensamento da autora, não há possibilidade de desvencilhar o conceito de política do conceito de público e liberdade, embora permaneçam em concepções distintas. A privação de qualquer direito reservado ao ser humano como, por exemplo, a educação, a liberdade, alimentação é suficientemente forte para estilhaçar o espaço político já que a condição de cidadão se encontra debilitada. Pelo entendimento de Schio (2012), o indivíduo torna-se político quando pode gozar das questões sociais que são comuns e partilhadas a todos, participando da vida em sociedade e usufruindo do papel de cidadão.

A noção de partilha também é expressa por Rancière (2010) ao avaliar o potencial da estética de promover ações políticas. A reflexão que o autor traz sobre política não é exatamente a mesma idealizada por Arendt, entretanto, ambos apresentam como ponto em comum a partilha de um sentido que permite a legitimação do campo da política $\mathrm{O}$ autor também acredita que o movimento de partilha dentro do universo das artes e da estética é uma ação política não exatamente pela capacidade de referencial das propostas discursivas

\footnotetext{
${ }^{1}$ É importante considerar que na Grécia antiga escravos, estrangeiros, mulheres e crianças não eram considerados livres pela condição de dependência a alguma outra pessoa ou situação para a sobrevivência, ou seja, eram desprovidos do sentido de cidadania.
} 
da obra, mas enquanto um modo de reverberação pela partilha da sensibilidade da arte. Rancière acredita que a política advém daqueles que se colocam como:

(...) habitantes de um espaço comum e para demonstrar que sim, suas bocas emitem uma palavra que enuncia algo do comum e não apenas uma voz que sinaliza a dor. Essa distribuição e essa redistribuição dos lugares e das identidades, esse corte e recorte dos espaços e dos tempos, do visível e do invisível, do barulho e da palavra constituem o que chamo da partilha do sensível. A política consiste em reconfigurar a partilha do sensível que define o comum na comunidade, em nela introduzir novos sujeitos e objetos, em tornar visível o que não era visto e fazer ouvir como falantes os que eram percebidos como animais barulhentos (Rancière 2010: 21).

Os propósitos de oferta de visibilidade, de reconhecimento social e capacidade de desenvolver comunicação são o que fazem da revista Nin uma forma de oportunizar a presença de signos, de sujeitos e de subjetividades invisibilizados no cenário público por uma questão de poder: gays, travestis, profissionais do sexo, ex-atriz pornô, a gordura corpórea, os pelos, a menstruação servem de argumento para reconhecer as várias facetas das sexualidades e como podem ser empreendidas como ações políticas a partir do momento que passam a circular em sociedade.

\section{Nin no campo da política}

Conforme apresentado anteriormente, Nin é uma revista erótica em que as margens de delimitação das sexualidades e identidades estão flexíveis e em movimento. Qualquer ação no sentido de formatar as perspectivas identitárias da publicação estará voltada ao fracasso; o que a rege é a variedade dos modos das representações das sexualidades que são abafadas enquanto articulações de poder. Além disso, a revista sinaliza a necessidade de debater as sexualidades e o erotismo para além dos atos sexuais e apontar para o fato de que os prazeres podem ser encontrados em práticas do cotidiano, no prazer de ouvir alguma música, na degustação de alimentos e bebidas ou na apreciação da arte. 
$\mathrm{Na}$ primeira edição da revista, que trouxe a ex-atriz pornô Cicciolina na capa para o empoderamento das mulheres pela sexualidade, Ronaldo Lemos (2015) aborda no texto Sexo $\mathcal{E}$ desigualdade a intenção de refletir sobre o tema e traz à tona considerações sobre essa questão ao abordar o funk como uma possibilidade libertária da sexualidade feminina. Ainda no mesmo texto, ele aponta as desigualdades sofridas por sujeitos LGBTs (lésbicas, gays, bissexuais, travestis, transexuais e transgêneros) em diálogo com o pensamento de Donna Haraway, apresentado na obra Manifesto ciborgue. No entendimento de ambos os autores, o ciborgue é manifestação de liberdade do corpo e da fluidez das identidades, um ponto que legitima a condição de transexuais e travestis no cenário político e público e também de propostas feministas.

Na visão dela [Donna Haraway], o ciborgue somos nós, sujeitos possíveis que podem transcender as dualidades (pulsão-detenção, abstinência-indulgência, homem-mulher, euoutro, cultura-natureza, civilizado-primitivo, certo-errado). O ciborgue é um símbolo de liberdade e de igualdade, que opera em antidiscriminação (o "eu" e o "outro" nos tornamos indistintos). Por conta disso, Haraway nos convoca a uma revisão do conceito de gênero, que deixe de ser patriarcal e essencialista. (Lemos 2015: 91)

Na mesma edição, amparado no pensamento de Wilhem Reich, João da Mata, apresenta o texto com o título Erotismo, sensualidade $\mathcal{E}$ sexualidade como potências da vida em que ilustra como a vida pode ser repleta de experiências de prazer para além do ato sexual. De acordo com Reich, movimentos do dia a dia podem ser dotados de modo libertário e legítimo; e o corpo pode ser um instrumento para esse caminho:

Uma experiência sensualista diz respeito ao mundo das sensações, que percorre o corpo afetado pelos sentidos. Assim, é possível sentir uma certa dose de sensualidade no ato de comer uma boa comida, de escutar uma boa música ou contemplar a beleza. Ou seja, a sensualidade está relacionada a todo prazer que afeta o corpo. Uma existência erótica, percorrida da sensualidade, não precisa apenas do ato sexual. Ela está presente nos pequenos gestos do dia a dia, intensificando a vida, percorrida por energias e vitalismo. O que torna o erotismo algo pornográfico é fruto da mesma moral conservadora, base de uma cultura patriarcal, que procura suprimir os impulsos sensuais e naturais. (Mata 2015: 65-66) 
Pela perspectiva traçada por Mata, o prazer não deveria ser embasado exclusivamente nos gestos da transa, mas deveria ser sentido também em outras esferas da vida sob outros contextos da vida cotidiana como ouvir música, alimentar-se bem, por exemplo, isso é sensual e também provoca prazer. Acompanhando a matéria, tem o ensaio fotográfico de Lídia O. composto por autorretratos. Nua e com a cabeça raspada, a fotógrafa posa mostrando a silhueta mais corpulenta, suas tatuagens na pele melânica e suas formas mais arredondas, representações que possivelmente não estampariam páginas de revistas eróticas mais convencionais.

Figura 1 - Ensaio de Lídia O.

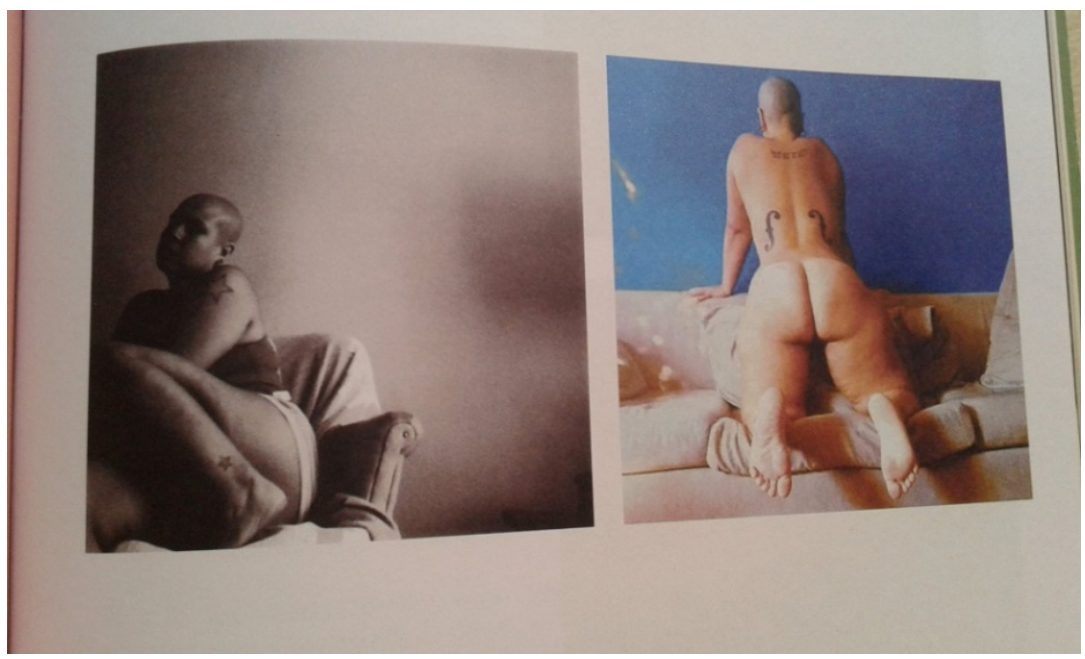

Fonte: Revista Nin, $1^{\underline{a}}$ ed. $p, 63$.

A interação entre imagens e textos pode fazer distante num primeiro momento, todavia, quando o autor do texto aborda outras formas de prazer, as fotografias de Lídia O. são frutíferas na medida em que evidencia outra estética do corpo para além do corpo esbelto, magro ou talhado pela rigidez dos músculos; o corpo da artista evidencia a gordura, as curvas generosas e uma composição corpórea para além daquilo que se prevê do erotismo midiático feminino.

Vagina, nádegas e quadris também são os motivos das representações de Aleta Valente, artista plástica e performer carioca, que apresentou seus trabalhos na segunda edição da revista. Essa edição trouxe o ensaio fotográfico da modelo Camila Ribeiro, modelo transexual que apresentou um pouco da sua vida em entrevista a Maria Clara Drummond. 
Aleta é formada em Belas Artes pela Universidade Federal do Rio de Janeiro (UFRJ) e para essa edição ela traz em suas imagens o deboche, o escárnio, o desaforo, porções suficientemente perversas para desafiar as estruturas marmorizadas dos discursos e modos de representação nas artes e também das manifestações mais contemporâneas das práticas e discursos feministas, além de serem audaciosas na perspectiva apresentada por Rancière de promover ações políticas sobre aquilo que muitas vezes é silenciado.

Aleta nasceu e mora no subúrbio carioca, mais precisamente em Bangu, mesmo bairro onde se encontra um dos maiores presídios do estado do Rio de Janeiro. O subúrbio, além de fazer parte do seu cotidiano, é também o cenário de muitos dos seus trabalhos como os muros sem rebocos e os terrenos repletos de lixos urbanos e restos de materiais de construção, "Territórios silenciados nas disputas de imaginário da cidade". (Bentes 2017: 106), um outro motivo para o seu deboche

A artista teve de lidar também com questões de ordem financeira e familiar: a maternidade precoce e as adversidades com os internamentos da mãe dela em clínicas de pessoas com transtornos mentais. Para expor alguns de seus trabalhos, ela mantém um perfil no Instagram (@ex-miss_febem²). Dessa condição árida e vulnerável, Aleta fez motivo para suas expressões de vida e de produção artística. O texto Pelos, poses e apelos, de Letícia Gicovate, aponta para o fato que Aleta ser uma artista "marginal, mesmo que se não quisesse ser" (2016: 59).

Figura 2 - Ensaio Aleta Valente

\footnotetext{
${ }^{2}$ Febem (Fundação para o Bem-estar do Menor) foi uma instituição socioeducativa para abrigar crianças e adolescentes em conflito com a lei ou em estado de vulnerabilidade que possibilitaria a adoção. Hoje a instituição não existe mais sendo substituída por outros órgãos que desempenham funções semelhantes.
} 


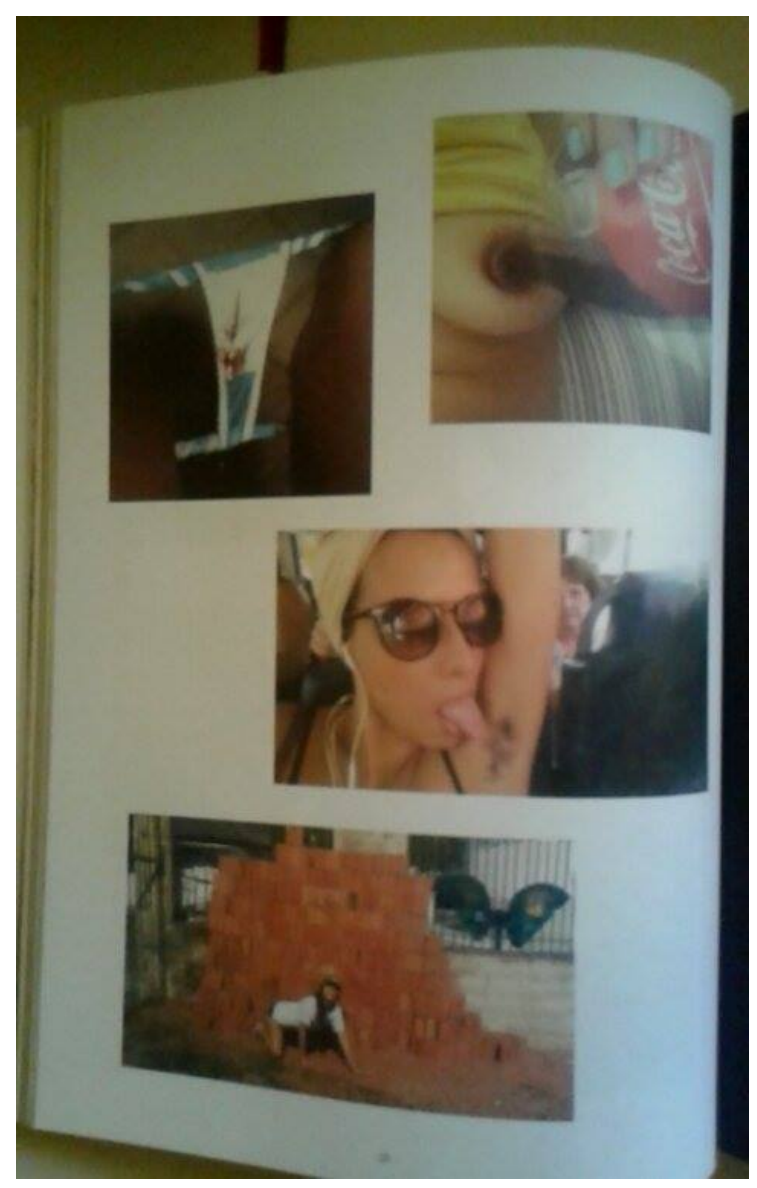

Fonte: Revista Nin, no2, p.58

Quando a artista traz à tona signos que são geralmente escondidos, ela também reconfigura os valores das artes contemplando o abjeto, aquilo que deveria ser esquecido, o abominável: a menstruação, os pelos das axilas e até mesmo o cenário árido da periferia carioca. Evidenciar esses elementos é repugnante sob o ponto de vista de controle dos corpos e manifestações de poder, considerados como sendo do "domínio das monstruosidades e das aberrações. Ou quiçá, pior ainda: da invisibilidade" (Sibila 2006: 277), e por isso a intenção de recalca-los, ainda mais tratando-se das representações imagéticas da cultura midiática do corpo e do erotismo. O estilo de performance, uma das estéticas utilizadas por Aleta, é um ato perverso na medida em que revalida a arte enquanto prática discursiva e também oferece outro tom aos espaços de prática e exposição das artes. A proposta discursiva de Aleta é considerada por Bentes (2017) como sendo o contradiscurso da visibilidade articulada ao escândalo do choque como sendo clara proposta de enfrentamentos. Por isso, 
ela denomina a sua prática como sendo a estética do escândalo e da subversão, a intensão de promover o desafio às ordens de poder:

Imagens de um corpo feminino que funciona como contradiscurso, a partir de uma visibilidade máxima, uma estética do escândalo, que usa a sedução, o erotismo, o humor, a inversão, o choque e o consumo para descontruir tabus, inventar novos lugares de fala. (...) A superexposição e a estética do escândalo e da subversão são utilizadas contra a censura, a vergonha, a vulnerabilidade dos corpos e também contra sua forma mercadológica de exposição, em uma sociedade em que o corpo das mulheres é utilizado para vender pneu, cerveja, comida, carro, detergente, sabão em pó, casa, tudo. (2017: 97-100)

É desta forma que no texto da revista, Colassanti (2016) sublinha que o trabalho de Aleta é a um diálogo com a resistência:

(...)com fins de protesto, uma performance cotidiana com fins de crítica social, uma performance em processo que confronta as normas culturais vigentes, com vistas a uma transformação da realidade, a libertação do corpo da mulher, a dissolução da ideologia machista dominante e o fim das minorias (...). (Colassanti 2016: 63)

O texto e as imagens sobre o trabalho de Aleta evidenciam a necessidade de descortinar o corpo e a condição da mulher de modo mais próximo do real, perverso por instruir para além daquilo que é permitido das representações imagéticas midiáticas. Além dos posicionamentos realizados, as imagens da artista também se propõem a enfrentar o patriarcado. No entendimento de Badinter (1987) que o patriarcado não é apenas uma forma de opressão sexual, mas também um sistema político que se estrutura ao compasso de códigos culturais. Entre as imagens de Aleta, uma em especial debocha da sexualidade e ironiza as belas artes de modo a estabelecer posicionamento questionador sobre os elementos que compõem os discursos e práticas artísticas. Evidenciando a própria vagina 
com sangue de menstruação, a artista chama a obra de L'origine du nouveau monde, uma analogia à tela L'origine $d u$ monde, de Colbert. Na matéria que acompanha a apresentação da imagem, Colassanti ainda apresenta a função da poesia, no caso, do trabalho de Aleta, “(...) O papel da poesia é criar novos sentidos, abrir brechas nas sensibilidades (...) O papel da poesia é desorganizar o dado, o instituído, o fixo para nos fazer ver o que não conseguimos ver de outra forma" (2016: 64).

Figura 3 - Ensaio de Aleta Valente "L'origine du nouveau monde"

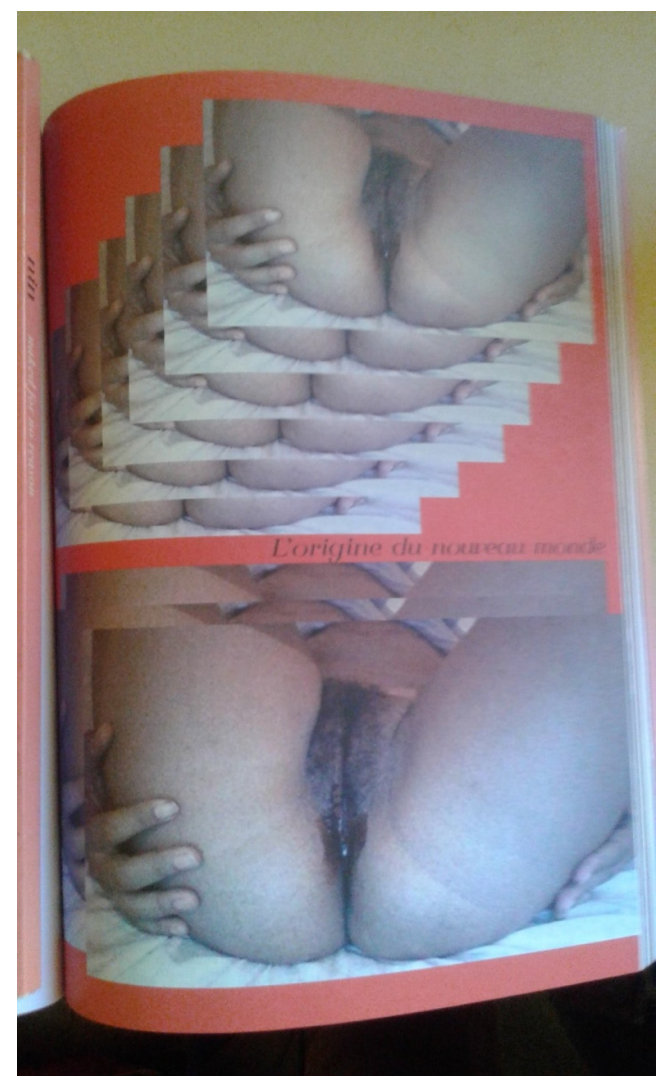

Fonte: Revista Nin, nำ, p.63

Por esses meandros que a colocação de Gayle Rubin (2003) se torna eficaz e eficiente para analisar a proposta editorial da revista e dos trabalhos das artistas. De acordo com a autora, há a vontade de uniformizar os desejos de tal modo que os tornem (ou ao menos tentem tornar-se) um sistema universal para todos e a falta de partilha desse código homogeneizante passaria a ser sintoma de mau gosto ou de algum problema de ordem mental, ou até mesmo de falta de inteligência, sem reconhecer as subjetividades que permeiam práticas que operam para além da condução heteronormativa. 
Considerar as manifestações artísticas de Lídia O. e de Aleta Valente como perversas, bem como as linhas editoriais de Nin, é transgredir os limites daquilo que é previamente conhecido, dos conceitos de corpo e da sexualidade, abrindo espaços para outras medidas de reconhecimento da condição heteronormativa ou das representações midiáticas estigmatizadas sobre o corpo e sexualidade. Perverso, nesse sentido, é ir além das barreiras estabelecidas pelo senso comum e contemplar representações, estéticas e signos que foram recalcados sem possibilidades de pudor.

\section{Considerações finais}

O discurso de Nin oferece a intenção de desafiar, afrontar e subverter a ordem das leis previamente estabelecidas. Isso é política a partir do momento em que há a partilha de outros sentidos para além daqueles estabelecidos por alguma força de poder. Assim, a ação da revista é sintoma da necessidade de um tempo que não acabe mais a penumbra de uma condição subalterna. Quando fizermos resgate histórico, veremos que em vários momentos as artes desafiaram paradigmas e leis, sendo consideradas sintomas de estratégias de resistências a movimentos de poder. Assim foi com a literatura erótica de Cassandra Rios e Adelaide Carraro e até mesmo a literatura de Jorge Amado que teve a obra Capitães da areia ardendo em fogo em praça pública na capital baiana, Salvador, ao ser considerada subversiva e fazer apologia ao comunismo, sendo assim, considerado uma ameaça à moral vigente.

No cinema, por exemplo, Pier Paolo Passolini também desafiou a moral e os bons costumes ao escancarar práticas coletivas sexuais nas telas do cinema no filme Saló 120 dias em Sodoma (1975). John Waters também não teve pudor ao retratar práticas incestuosas e ingestão de fezes por uma drag-queen no filme Pink Flamingos (1972). Discursos considerados perversos pelo enfrentamento proposto e que fizeram sentido no momento pela audácia e ousadia com quem foram produzidos. A arte talvez seja um dos discursos mais apropriados pelo fomento de iniciativas de resistência e enfrentamento. A liberdade com que pode ser produzida constrói signos políticos para fortalecer representatividades e visibilidades da condição humana, a despeito de ainda haver dificuldades de acesso e de visibilidade. Alguns dos filmes citados foram proibidos de exibição em países como o Brasil, a revista Nin tem o mérito de escancarar a visibilidade de sexualidades dissidentes, entretanto, não circula para grande público em bancas de jornais. 
Pelas palavras de Dufor (2013), os perversos e insubmissos são importantes e necessários justamente porque encontram forças para desafiar os sistemas mais herméticos e fechados. Pela compreensão do autor, há a necessidade de ser perverso em consonância com a intenção de burlar esses sistemas e, assim, alargar os modos de representação e sentido sobre determinados signos. Essa perspectiva de ação é o que engrandece as manifestações políticas e também reconfigura os espaços públicos já que promove o enfrentamento que propõe a visibilidade e a ação política de sujeitos marginalizados pelas práticas de poder.

É importante pontuar que por ser uma revista, Nin também apresenta alguma perspectiva mercadológica quanto à comercialização, entretanto, a condição de estar inserida no circuito midiático não obrigatoriamente oferece razões suficientemente fortes para apontar que o objetivo exclusivo da revista seja a obtenção de lucro. A contribuição da revista pode ir além do ponto de vista econômico e atravessar a necessidade de reconfiguração cultural por demandas de legitimação das sexualidades, do desejo e do sexo pela partilha de representações que não se encontram mais estáveis e cristalizadas. Além disso, ela oferece visibilidade e tenta, de algum modo, o enfrentamento de discursos e práticas conservadoras sobre a sexualidade que permeia o patriarcado, o machismo e a misoginia. A revista é o sintoma de um tempo pela precisão de reconfigurar representações e sentido dos corpos e dos desejos.

Analisar as representações da revista e reconhecê-las como outras propostas das sexualidades possíveis é conferir a existência de sujeitos e subjetividades para além dos códigos heteronormativos e convencionais das identidades e gêneros dentro do espaço político de visibilidade e também midiático. A perversão, quando trabalhada segundo preceitos da política, traz contribuições significativas para a visibilidade de sujeitos marginalizados e periféricos.

Em localizações de cultura patriarcal, mudanças culturais para o reconhecimento de sexualidades dissidentes sempre serão caminhos longos e tortuosos, ainda mais porque promovem o incômodo e a movimentação de camadas mais conservadoras da cultura. Todavia, propostas como a da revista Nin abrem clareias para reflexões sobre as sexualidades, pela sensibilidade de partilhar desejos e signos considerados aberrantes como sendo, na verdade, dignos da condição humana como outros quaisquer. Refutar a existência da diversidade de subjetividades e desejos é escamotear os movimentos de vida, castrando cidadãos da possibilidade política de visibilidade. 


\section{Referências bibliográficas}

Amaral, M. E. P. do, and Arias Neto, J. M. 2018. 'A montagem perversa positiva na revista Nin'. Revista Famecos 25 (1) : 1-27. doi: http://dx.doi.org/10.15448/1980-3729.2018.1.26869

Arendt, Hannah. 1992. Entre o passado e o futuro. São Paulo: Nova Perspectiva.

Badinter, E. 1987. Um é o outro. Lisboa: Relógio d'Água.

Baker, Chris; Jane, Emma A. 2016. Cultural studies: theory and practice. $5^{\underline{a}}$ ed. London: Sage Publications.

Bentes, I. 2017. 'Biopolítica feminista e estéticas subversivas'. Revista Matrizes 11 (2): 93-109. doi: http://dx.doi.org/10.11606/issn.1982-8160.v11i2p93-109

Butler, Judith. 2003. Problema de gênero: feminismo e subversão de identidade. Rio de Janeiro: Civilização Brasileira.

Colassanti. Alice. 2015. 'Aleta Valente, a boca do novo mundo'. Revista Nin.

Dufor, Dany R. 2013. A cidade perversa: liberalismo e pornografia. Rio de Janeiro: Civilizações Brasileiras.

Foucault, Michel. 1993. A história da sexualidade 1: a vontade de saber. 11. ed. Rio de Janeiro: Graal.

Foucault, Michel. 1998. Microfísica do poder. Rio de Janeiro: Graal.

Freud, Sigmund. 1996/1905. Obras psicológicas completas de Sigmund Freud: volume VII. Um caso de histeria: Três ensaios sobre sexualidade e outros trabalhos. Rio de Janeiro: Imago.

Gicovate, Letícia. 2016. 'Pelos, posses e apelos'. Revista Nin.

Lemos, Ronaldo. 2015. 'Sexo \& desigualdade'. Revista Nin.

Louro, G. L. 2001. 'Teoria queer - uma política pós-identitária para a educação'. Revista Estudos Feministas 9 (2): 541-553. doi: http://dx.doi.org/10.1590/S0104-026X2001000200012. 
Mata, João da. 2015. 'Erotismo, sensualidade \& sexualidade como potências da vida'. Revista Nin.

Rancière, Jacques. 2005. Partilha do sensível. São Paulo: Editoria 34.

Rancière, J. 2010. 'A estética como política'. Revista Devires 7 (2): 14-36.

Roudinesco, Elisabeth. 2008. A parte obscura de nós mesmos: uma história dos perversos. Rio de Janeiro: Zahar.

Rubin, G. 2003. 'Pensando sobre sexo: notas para uma teoria radical da política da sexualidade'. Cadernos Pagu 21 (2): 1-88.

Sibilia, Paula. 2006. 'O bisturi de software: como fazer um "corpo belo" virtualizando a carne impura?’ In Imagem (Ir) realidade: comunicação e hipermídia, 277. Porto Alegre: Sulina.

Schio, Sônia Maria. 2012. Hannah Arendt: história e liberdade: da ação à reflexão. 2ª ed. Porto Alegre: Clarinete.

Silva, Tomaz Tadeu da. 2000. Documentos de identidade: uma introdução às teorias do currículo. Belo Horizonte: Autêntica. 